\title{
Defining the molecular response to trastuzumab, pertuzumab and combination therapy in ovarian cancer
}

\author{
AH Sims', I,4, AJM Zweemer ',4, Y Nagumo',3, D Faratian', M Muir', M Dodds', I Um', C Kay', M Hasmann², \\ DJ Harrison' and SP Langdon'
}

'Edinburgh Breakthrough Research Unit, Division of Pathology, Institute of Genetics and Molecular Medicine, University of Edinburgh, Western General Hospital, Crewe Road South, Edinburgh EH4 2XU, UK; ${ }^{2}$ Roche Diagnostics GmbH, Penzberg, Germany

BACKGROUND: Trastuzumab and pertuzumab target the Human Epidermal growth factor Receptor 2 (HER2). Combination therapy has been shown to provide enhanced antitumour activity; however, the downstream signalling to explain how these drugs mediate their response is not clearly understood.

METHODS: Transcriptome profiling was performed after 4 days of trastuzumab, pertuzumab and combination treatment in human ovarian cancer in vivo. Signalling pathways identified were validated and investigated in primary ovarian xenografts at the protein level and across a timeseries.

RESULTS: A greater number and variety of genes were differentially expressed by the combination of antibody therapies compared with either treatment alone. Protein levels of cyclin-dependent kinase inhibitors p2I and p27 were increased in response to both agents and further by the combination; pERK signalling was inhibited by all treatments; but only pertuzumab inhibited pAkt signalling. The expression of proliferation, apoptosis, cell division and cell-cycle markers was distinct in a panel of primary ovarian cancer xenografts, suggesting the heterogeneity of response in ovarian cancer and a need to establish predictive biomarkers.

CONCLUSION: This first comprehensive study of the molecular response to trastuzumab, pertuzumab and combined therapy in vivo highlights both common and distinct downstream effects to agents used alone or in combination, suggesting that complementary pathways may be involved.

British Journal of Cancer (2012) 106, 1779-1789. doi:10.1038/bjc.2012.176 www.bjcancer.com

Published online I May 2012

(C) 2012 Cancer Research UK

Keywords: ovarian; microarray; combination; trastuzumab; pertuzumab

A number of targeted therapies are currently under intense clinical evaluation for use in ovarian cancer due to the heterogeneity of the disease and the poor prognosis of patients (Banerjee and Gore, 2009; Yap et al, 2009). One approach being investigated is the potential of Human Epidermal growth factor Receptor (HER) 2-directed therapy, since increased HER2 (erbB2) expression has been associated with poor survival and resistance to platinumbased therapy (Serrano-Olvera et al, 2006) and preclinical data support the concept of using these inhibitors (Takai et al, 2005; Mullen et al, 2007). Both antibody (trastuzumab and pertuzumab) and small tyrosine kinase inhibitor (lapatinib) approaches have recently undergone clinical trials in this disease (Bookman et al, 2003; Burris et al, 2005; Gordon et al, 2006; Kaye et al, 2008; Rivkin et al, 2008; Makhija et al, 2010). Trastuzumab has been evaluated in high HER2 expressing ovarian cancer and in this group, while only $7.5 \%$ of patients showed a response, $39 \%$ demonstrated stable disease (Bookman et al, 2003). Pertuzumab has shown a clinical benefit rate of $14.5 \%$ when RECIST responders, CA125 responders and stable disease at 6 months were combined (Gordon et al, 2006).

*Correspondence: Dr AH Sims; E-mail: andrew.sims@ed.ac.uk

${ }^{3}$ Current address: Graduate School of Life and Environmental Sciences, University of Tsukuba, I- I - I Tennodai, Tsukuba, Ibaraki 305-8572, Japan. ${ }^{4}$ These authors contributed equally to this work.

Received 17 February 2012; revised 3 April 2012; accepted 3 April 2012; published online I May 2012
This led to several large phase II studies evaluating pertuzumab in both platinum-resistant disease in combination with gemcitabine (Makhija et al, 2010) and in platinum-sensitive disease (Kaye et al, 2008). Lapatinib (GW572016), a dual HER2/EGF receptor inhibitor, has been studied in two combination studies alongside chemotherapy and demonstrated antitumour activity (but also toxicity), which again supports the concept of targeting HER2 in ovarian cancer (Burris et al, 2005; Rivkin et al, 2008).

The antibodies trastuzumab and pertuzumab target different epitopes of HER2 (Badache and Hynes, 2004) and have differing modes of action (Franklin et al, 2004; Spector and Blackwell, 2009). Trastuzumab binds to the juxtamembrane region of the extracellular domain (ECD) of HER2 (subdomain IV) and in breast cancer demonstrates best activity against HER2-overexpressing disease. It has been shown to act through a variety of differing mechanisms including antibody-dependent cellular cytotoxicity (ADCC), inhibition of ECD cleavage, abrogation of intracellular signalling, reduction of angiogenesis and decreased DNA repair (Spector and Blackwell, 2009). Pertuzumab is an HER2 dimerisation inhibitor that binds to HER2 near the centre of domain II, the dimerisation domain (Franklin et al, 2004). Unlike trastuzumab, the effects of pertuzumab do not strictly require HER2 overexpression and therefore pertuzumab may be a better choice against tumours expressing HER2 at a lower level. For example, pertuzumab inhibits heregulin-stimulated growth mediated by HER2/HER3 dimers of breast cancer cells, whereas trastuzumab is more efficient at growth inhibition in the absence of heregulin 
(Lee-Hoeflich et al, 2008). Besides inhibition of dimerisation, pertuzumab mediates ADCC in a similar way as mentioned above for trastuzumab (Clynes et al, 2000). A recent study demonstrated enhanced antitumour activity of trastuzumab and pertuzumab combination in HER2-positive NSCLC (Calu-3) and breast cancer (KPL-4) xenograft tumour models (Scheuer et al, 2009). Results from the clinical evaluation of pertuzumab and trastuzumab (CLEOPATRA) study have demonstrated that addition of pertuzumab to trastuzumab plus docetaxel extended progression-free survival from 12.4 to 18.5 months for HER2-positive metastatic breast cancer indicating the clinical benefit from combination of these two antibodies (Baselga et al, 2012).

To identify which patients will respond to these agents either alone or in combination, there is a need to characterise the molecular response and identify predictive biomarkers to guide treatment selection. Gene expression profiling has previously been used to characterise the effects of different agents in vivo (Taylor et al, 2010).

This study is the first to define the molecular response to trastuzumab and pertuzumab in ovarian cancer in vivo. We assessed the effects of the treatments on gene expression, proliferation and apoptosis in SKOV3 xenografts, both individually and in combination. Potential biomarkers and pathways were validated by quantitative real-time PCR (qRT-PCR). Changes in gene expression were evaluated at the protein level and then across a panel of primary ovarian xenografts. Together, these studies provide insight into the mechanisms of trastuzumab and pertuzumab in ovarian tumours, which may also be applicable to other cancers.

\section{MATERIALS AND METHODS}

\section{Xenografts}

Adult female nu/nu mice were implanted subcutaneously with SKOV3 tumour fragments (previously established from the cell line) or primary ovarian tumour fragments in the flanks and allowed to grow to $4-6 \mathrm{~mm}$ in diameter (over a period of $\sim 1$ month). Animals were at least 8 weeks old at the time of experimentation and were maintained in negative pressure isolators (La Calhene, Cambridge, UK). The mice were treated with trastuzumab $\left(20 \mathrm{mg} / \mathrm{kg}^{-1}\right)$, pertuzumab $\left(20 \mathrm{mg} / \mathrm{kg}^{-1}\right)$ and trastuzumab + pertuzumab $\left(20 \mathrm{mg} / \mathrm{kg}^{-1}\right.$ each $)$. Drugs were given via the intraperitoneal route in saline on days $0,3,7$ and 10 . Tumour size was measured twice weekly using calipers and the volume calculated according to the formula $\pi / 6 \times$ length $\times$ width $^{2}$. Relative tumour volumes (\%) were then calculated for each individual tumour by dividing the tumour volume on day $t\left(V_{t}\right)$ by the tumour volume on day $0\left(V_{0}\right)$ and multiplying by 100 . The histological subtypes of the ovarian cancers from which the xenografts were derived were as follows: HOX 493 and OV1002 - serous histology; HOX 424 - mixed clear cell/ endometrioid histology; HOX 516 and HOX 486 - mixed serous/ endometrioid histology.

\section{Gene expression profiling and analysis}

Total RNA was prepared from 10 to $50 \mathrm{mg}$ of frozen tissue after 4 days of treatment, preincubated with RNAlater-ICE (Ambion, Austin, TX, USA) using the miRNeasy Mini kit (Qiagen, Hilden, Germany) and TissueRuptor (Qiagen) following manufacturers' instructions. The RNA quality was checked by the RNA 6000 Nano assay on the Agilent Bioanalyzer (Agilent Technologies, Santa Clara, CA, USA). RNA integrity numbers were $>8.5$. All samples were divided into two identical aliquots for independent labelling and hybridisation. Total RNA for each sample $(-0.5 \mu \mathrm{g})$ was amplified and biotinylated using the Illumina TotalPrep RNA Amplification Kit (Ambion) according to manufacturers' standard procedure. This procedure consists of reverse transcription with an oligo(dT) primer bearing a $\mathrm{T} 7$ promoter using a reverse transcriptase (RT). The quality and quantity of cRNA in the samples was checked with an Agilent Bioanalyzer 2100 (Agilent Technologies), samples were diluted to $150 \mathrm{ng} / \mu \mathrm{l}^{-1}$ and hybridised to Illumina HT-12 BeadChips in duplicate (Illumina, San Diego, CA, USA).

Microarray data analysis was performed using the statistical programming language $\mathrm{R}$ and Bioconductor packages. Illumina probe profile expression values were subjected to quantile normalisation using the lumi package. Differentially expressed genes were identified using Significance Analysis of Microarrays (SAM; Tusher et al, 2001), implemented with the siggenes package. Centred average linkage clustering was performed using the Cluster and TreeView programs as described previously (Eisen et al, 1998). The online Database for Annotation, Visualisation and Integrated Discovery (DAVID) programme (Huang da et al, 2009) was used to identify overrepresented KEGG (Kyoto Encyclopaedia of Genes and Genomes) pathways from lists of differentially expressed genes. Raw and processed gene expression files have been submitted to NCBI Gene Expression Omnibus (https://www.ncbi.nlm.nih.gov/geo/) under the accession number GSE31432.

\section{Western blot analysis}

Xenografts were lysed in $50 \mathrm{~mm}$ Tris $\mathrm{pH} 7.5,150 \mathrm{~mm} \mathrm{NaCl}, 1 \%$ Triton X-100, $5 \mathrm{~mm}$ EGTA, $10 \mu \mathrm{g} \mathrm{ml}^{-1}$ aprotinin (Sigma-Aldrich, St Louis, MO, USA), Complete Protease Inhibitor Cocktail (Roche, Basel, Switzerland) and Phosphatase Inhibitor Cocktail 1 and 2 (Sigma-Aldrich) and spun for $10 \mathrm{~min}$ at $16000 \mathrm{~g}$ at $4^{\circ} \mathrm{C}$. The protein content of the resulting supernatant was determined by the Bicinchoninic acid protein assay (Sigma-Aldrich). Protein lysates were electrophoretically resolved on $7.5-10 \%$ SDS-PAGE and transferred onto Immobilon-P membranes. After transfer, membranes were blocked with $1 \%$ blocking agent (Roche) in TBS before probing overnight at $4{ }^{\circ} \mathrm{C}$ with the appropriate primary antibody. Antibodies used for western blotting were as follows: antiphosphorylated HER1 (pHER1) (Tyr ${ }^{992}$; Cell Signaling Technology, Danvers, MA, USA) at 1:1000; anti-phosphorylated HER2 (pHER2) $\left(\mathrm{Tyr}^{877}\right.$; Cell Signaling Technology) at 1:1000; anti-phosphorylated HER3 (pHER3) (Tyr ${ }^{1289}$; Cell Signaling Technology) at $1: 1000$ and anti-actin (Merck, Whitehouse Station, NJ, USA). For detection of the ECD of HER2, NeoMarkers c-erbB2 antibody Ab-20 (MS-1350) was used while the Dako anti-HER2 antibody from the Hercept test was used to detect the $\mathrm{C}$-terminal domain. Immunoreactive bands were detected using enhanced chemiluminescent reagents (Roche) and Hyperfilm enhanced chemiluminescence film (Amersham, Little Chalfont, Buckinghamshire, UK). Integrated absorbance values were obtained by densitometric analysis using a gel scanner and analysed by Labworks gel analysis software (UVP Life Sciences, Cambridge, UK).

\section{Quantitative RT-PCR}

RNA $(1 \mu \mathrm{g})$ was reverse transcribed using QuantiTect Reverse Transcription kit (Qiagen) according to manufacturers' instructions, 100-fold dilutions were used, except for primers KLK11, transforming growth factor, $\beta$-induced (TGFBI) and PTPRR for which a 10 -fold dilution was used. The amount of cDNA was quantified using Rotorgene (Corbett Research, San Francisco, CA, USA) and the QuantiTect SYBR Green system (Qiagen) according to manufacturers' instructions. Primers were from Qiagen, except KLK11 (Sigma-Aldrich), PCRs on RNA samples which had not been reverse transcribed were also carried out to check for genomic DNA contamination, these were all negative. The housekeeping gene GUSB was used as a reference gene, as its level was constant across the microarray results. 


\section{Tissue microarrays and immunohistochemistry}

Tissue microarrays (TMAs) for SKOV3 (four replicates) and primary tumour (two cores each) xenografts were produced using previously described techniques (Kononen et al, 1998). Haematoxylin and eosin sections of the tumour xenografts were reviewed by a pathologist and representative areas marked. Recipient blocks were prepared by melting paraffin and pouring into a 5- to $10-\mathrm{mm}$-thick mold. Immunohistochemistry was performed using a standard immunoperoxidase procedure. Sections were dewaxed and rehydrated before proceeding with antigen retrieval under pressure for $5 \mathrm{~min}$ in sodium citrate buffer $(8.2 \mathrm{~mm}$ citric acid, $1.8 \mathrm{~mm}$ sodium citrate, $\mathrm{pH}$ 6) or Tris-EDTA buffer ( $10 \mathrm{~mm}$ Tris, $1 \mathrm{~mm}$ EDTA, $0.05 \%$ Tween-20, pH 9). The slides were then treated with $3 \% \mathrm{H}_{2} \mathrm{O}_{2}$ for $10 \mathrm{~min}$ to quench peroxidase activity. Subsequently, they were incubated in serum-free block solution (Dako, Glostrup, Denmark) for $20 \mathrm{~min}$ to eliminate any unspecific background staining. Primary antibody incubations were Ki67 (DAKO; M7240) at 1:50; phosphoHistone H3 (Cell Signaling Technology; 9701) at 1:100; p27 (Cell Signaling Technology; 2552) at $1: 100$ for $1 \mathrm{~h}$ at room temperature; p21 (Cell Signaling Technology; 2946) at 1:100; anti-phosphorylated ERK (pERK) 1/2 (Cell Signaling Technology; 9101) at 1:25; antiphosphorylated Akt (pAkt; Ser ${ }^{473}$; Cell Signaling Technology; 4060) at 1:100; cleaved caspase 3, (\#9661 Cell Signaling Technology; $1: 200$ ) were used overnight at $4{ }^{\circ} \mathrm{C}$. EnVision (HRP Rabbit/Mouse; Dako) was used as secondary antibody and positive staining was detected by incubation with 3,3-diaminobenzidine solution (DAB + chromogen; Dako). Finally, the sections were counterstained with haematoxylin, dehydrated and mounted. Quantification of positivity $(0-100 \%)$ was based on an estimate of the percentage of immunoreactive tumour cells in the cores. For staining with cleaved caspase 3, phospho-histone $\mathrm{H} 3$ and $\mathrm{p} 21$, the immunoreactive nuclei were counted and divided by the total amount of tumour cell nuclei in each core. Statistical analysis of data obtained by immunohistochemistry was performed using the Mann-Whitney $U$-test.

\section{AQUA automated image analysis}

A detailed description of the AQUA HistoRx methodology is available elsewhere (Camp et al, 2002; Aitken et al, 2010). Pan-cytokeratin antibody was used to identify infiltrating tumour cells, DAPI counterstain to identify nuclei, and Cy-5-tyramide detection for target for compartmentalised (tissue and subcellular) analysis of tissue sections. Monochromatic images of each TMA core were captured at $\times 20$ objective using an Olympus AX-51 epifluorescence microscope (Olympus, Southend-on-Sea, UK), and high-resolution digital images analysed by the AQUAnalysis software (HistoRx, Branford, CT, USA). When whole tissue sections of xenograft tumours were analysed, the whole section was divided into $\times 20$ objective magnification images and an AQUA score generated for each frame for heterogeneity analysis. Briefly, a binary epithelial mask was created from the cytokeratin image of each TMA core. If the epithelium comprised $<5 \%$ of total core area, the core was excluded from the analysis. Similar binary masks were created for cytoplasmic and nuclear compartments based on DAPI staining of nuclei. Target expression was quantified by calculating the Cy5 fluorescent signal intensity on a scale of 0-255 within each image pixel, and an AQUA score was generated by dividing the sum of Cy5 signal within the epithelial mask by the area of the cytoplasmic compartment.

\section{HER2 FISH}

Gene amplification of HER2 was assessed by FISH using the Pathvysion HER2 DNA Probe Kit (Vysis, Downers Grove, IL, USA). The HER2 to CEP17 ratios of $>2.0$ were considered amplified.

\section{RESULTS}

\section{Common molecular responses to trastuzumab,} pertuzumab and combination therapy

Human epidermat growth receptor 2-expressing SKOV3 ovarian cancer xenografts were treated with trastuzumab alone, pertuzumab alone or combined antibody therapy. Pertuzumab slowed growth, whereas trastuzumab and combination treatment resulted in stronger growth inhibition, with the combination being most potent, giving a significant $(P<0.05)$ reduction in tumour volume by day 4 (Figure 1A). Differentially expressed genes after 4 days of treatment compared with untreated SKOV3 tumour xenografts were identified using the SAM approach (Tusher et al, 2001) with a $10 \%$ false discovery rate (FDR). Similar numbers of probes were differentially expressed (105 and 113) in response to either trastuzumab or pertuzumab alone, compared with untreated tumours (Figure 1B). Almost all the significantly changed genes were upregulated $(94 \%$ and $98 \%$ ) in tumours subjected to a single agent. Many more probes (555) were differentially expressed between the combination therapy and control groups, of which just over half were upregulated (55\%; Figure 1B). There was greater overlap (Figure 1C) between the genes differentially expressed by trastuzumab alone and the combination therapy (6\%) than between pertuzumab alone and the combination (2\%), which may relate to the more similar reduction in tumour volume observed (Figure 1A; full gene lists in Supplementary File 1). The KEGG pathways that were overrepresented by the gene lists identified using DAVID (Huang da et al, 2009) are shown in Table 1. Prominent among the gene lists for trastuzumab and pertuzumab single agent treatments were genes involved in the well-characterised p53, MAP kinase and not surprisingly (but reassuringly) the HER (ErbB) signalling pathways, including the FOS, JUN, DUSP1, SERPINB5, p53AIP1, HER3 and CDKN1A (p21).

\section{Different genes and pathways are activated or repressed in response to anti-HER2 agents}

Several distinct patterns of gene expression could be seen between the two treatments alone or in combination. Ten genes with differing patterns of expression across the treatments were validated by $\mathrm{qRT}-\mathrm{PCR}$, the fold changes were highly consistent with those established from the Illumina data, with a correlation coefficient $\left(R^{2}\right)$ of $0.97(P<0.0001$; Supplementary Figure 1$)$. Many of the genes that were most differentially expressed by combination therapy were also altered in trastuzumab-treated tumours, albeit to a lesser extent (FDR $>10 \%$; Figure 1D). These genes include the highly expressed serine protease, hippostasin (KLK11), oestrogen receptor $\alpha$ (ESR1) and the classic $\mathrm{E}_{2}$-response genes TFF2 and TFF3 (TFF1 had a similar pattern of expression (Pearson correlation coefficient $R=0.72$ ), but was not among those with an FDR $<10 \%)$, along with E-cadherin $(\mathrm{CDH} 1)$, see Figure $1 \mathrm{D}$ and Supplementary Figure 1. The same criteria as above (SAM $\mathrm{FDR}=10 \%$ ) was used to identify 119 genes whose expression was different between the response to the two agents administered separately. Two-thirds (80 out of 119) of these genes were higher following trastuzumab than pertuzumab treatment, although axon guidance was the only KEGG pathway highlighted (Table 1). Genes with discordant expression between the two agents were much more strongly correlated between trastuzumab and combination (Pearson $R^{2}=0.73, P<0.0001$ ) than between pertuzumab and combination $\left(R^{2}=0.03, P=0.14\right)$. This is consistent with the observation that the effects of trastuzumab dominate the molecular response when the agents are administered given together (Figure 1D). It was interesting to note that genes involved in chemokine/cytokine-receptor interactions (IL1A, IL6, IL8, CXCL1, CCL2, CCL26, IL4R, IL11RA) and genes associated with cell communication (CD40, CLDN1, PECAM1, VCAM1) were increased 
A

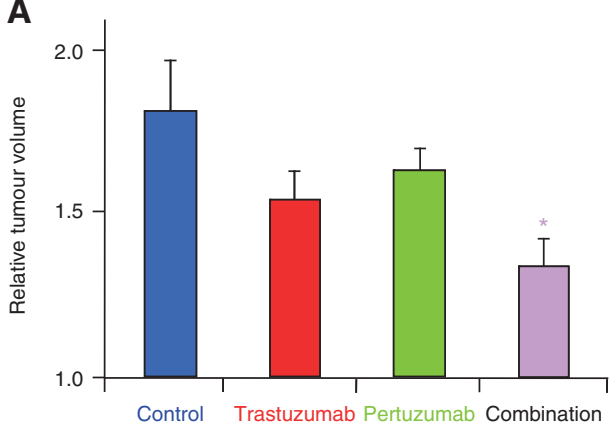

Both HER2 inhibitors and combination (3)

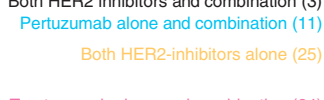

Trastuzumab alone and combination (34)

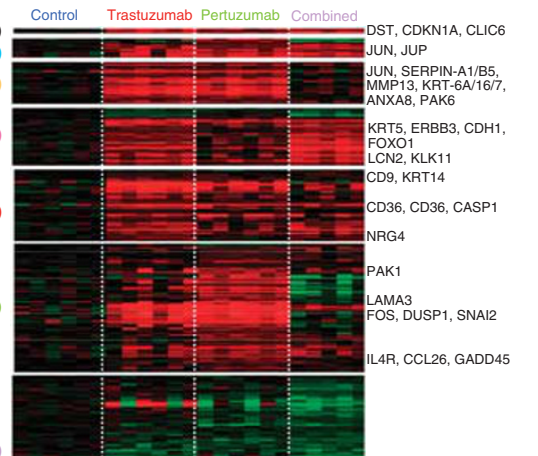

B
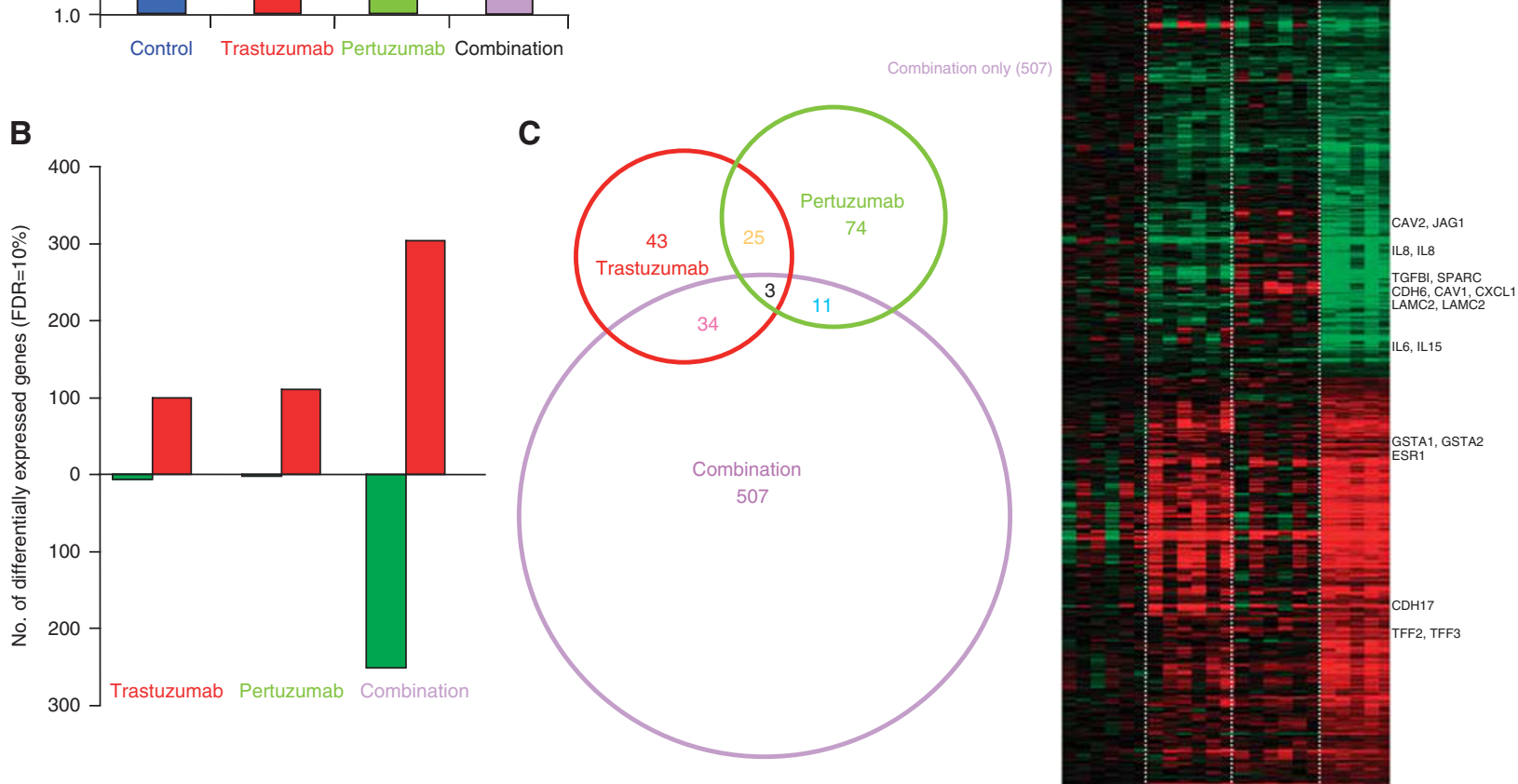

Figure I Common and differential molecular responses to trastuzumab and pertuzumab alone or in combination. (A) Reduction in tumour volume upon treatment with trastuzumab or pertuzumab or combination after 4 days, relative to day 0. Mean relative tumour volume of SKOV 3 tumour xenografts, $n=3$, error bars represent standard deviation $(* P<0.05)$. (B) Comparison of the number of differentially expressed genes with either agent or combination therapy relative to control, using SAM with $10 \%$ FDR cutoff. Red = upregulated, green = downregulated. (C) Venn diagram showing the overlap between in genes that were significantly differentially expressed between trastuzumab, pertuzumab and combination therapy (SAM FDR $=10 \%)$ after 4 days of treatment. The sizes of circles and overlaps are only roughly proportional to the number of genes. (D) Heatmap showing relative expression of 697 genes from Venn diagram, red represents increased expression and green decreased expression relative to the median of the controls.

following the treatment with pertuzumab, but were reduced following the treatment with trastuzumab and reduced further with the combination. Examples of genes that were more downregulated after combination therapy compared with either agent alone and validated with qRT-PCR were interleukin 8 (IL8) and TGFBI. A number ofkeratins (KRT6A, 8, 14, 16, 17, 19) and laminins (LAMC2, B3 and A3) associated with cell adhesion were more strongly increased by treatment with single agents than combination therapy. Genes of the MAPK signalling pathway including FOS and DUSP1 were more strongly induced by pertuzumab, while certain genes including ectonucleotide pyrophosphatase 2 (ENPP2) and matrix metalloproteinase 7 (MMP7) were only changed by the combination and not by single agents (Figure 1D; Supplementary Figure 1).

\section{Comparison of the transcriptomic response to previous studies of anti-HER agents}

Eight of the sixteen genes identified as downregulated in SKBR3 and BT474 breast cancer cells in vitro following the trastuzumab treatment (Le et $a l, 2005 \mathrm{a}$ ) were also significantly ( $t$-test, $P<0.05$ ) repressed by trastuzumab in this study (RFC4, BUB1B, SPAG5, AURKA, UBE2C, ZWINT, TYMS and FEN1), but only three genes were repressed by pertuzumab (RFC4, BUB1B and $H M G B 2)$ and the combination (RCF4, BUB1B and FEN1). The fact that these genes were not among those most significantly differentially expressed genes in our study (Supplementary Figure 2A) is likely to be a reflection of the more variable and complex responses observed in vivo. Indeed, a microarray study of responding and non-responding patients with locally advanced HER2-positive breast cancer treated with trastuzumab combined with docetaxel found that gene expression of classical cancer pathway genes related to apoptosis or DNA repair could not distinguish responding tumours (Vegran et al, 2009). Of the 28 genes not involved in classical cancer pathways that were used to predict response, only 4 (of the 25 out of 28 genes represented by our data) were commonly significantly upregulated/downregulated (Supplementary Figure 2B).

\section{HER receptor phosphorylation and downstream signalling}

To better understand the effects of trastuzumab, pertuzumab and the combination on activated HER receptor signalling, we first checked the phosphorylation status of HER2, together with its heterodimer partners HER1 and HER3. After 14 days of treatment, HER2 phosphorylation at Tyr ${ }^{877}$, an Src-dependent phosphorylation site, was increased in pertuzumab-treated tumours (Figure 2A). Pertuzumab also increased phosphorylation of 
Table I KEGG pathways overrepresented by genes differentially expressed with an FDR < I0\% (see Figure ID and full list in Supplementary File I)

\begin{tabular}{|c|c|c|c|}
\hline KEGG pathway & Genes & $P$-value & FDR \\
\hline \multicolumn{4}{|l|}{ Trastuzumab compared with control (I05 probes) } \\
\hline ErbB signalling pathway & PAK6, CDKNIA, NRG4, ERBB3 & 0.002 & 1.6 \\
\hline p53 signalling pathway & P53AIPI, CDKNIA, SERPINB5 & 0.06 & 47.2 \\
\hline \multicolumn{4}{|l|}{ Pertuzumab compared with control (I I 3 probes) } \\
\hline p53 signalling pathway & CDKNIA, SERPINB5, CD82, SFN, GADD45A & 0.003 & 2.7 \\
\hline Renal cell carcinoma & PAK6, CDKNIA, EPASI, JUN, PAKI & 0.003 & 3.0 \\
\hline ErbB signalling pathway & PAK6, CDKNIA, JUN, PAKI & 0.006 & 6.4 \\
\hline Focal adhesion & PAK6, CDKNIA, LAMA3, TNC, JUN, PAKI & 0.007 & 7.1 \\
\hline T-cell receptor signalling pathway & PAK6, FOS, CDKN IA, JUN, PAKI & 0.01 & |3.1 \\
\hline MAPK signalling pathway & FOS, DUSPI, ARRBI, JUN, PAKI, GADD45A,ILIA & 0.03 & 23.7 \\
\hline Pathways in cancer & JUP, FOS, CDKNIA, LAMA3, EPASI, JUN & 0.06 & 47.7 \\
\hline \multicolumn{4}{|l|}{ Combination compared with control (555 probes) } \\
\hline Arginine and proline metabolism & NOSI, CKM, ASSI, GLS, ALDH3A2 & 0.01 & 12.2 \\
\hline Metabolism of xenobiotics by cytochrome P450 & GSTA I, GSTA2, CYP2SI, UGT2A3, UGT2B I 5,ALDH3AI & 0.02 & 19.4 \\
\hline Glycerolipid metabolism & LIPG, MGLL, GK, ALDH3A2, AGPAT2 & 0.03 & 27.8 \\
\hline Epithelial cell signalling in Helicobacter pylori infection & CXCLI, IL8, JUN, ATP6VIE2, RACI, ATP6VOA2 & 0.03 & 29.7 \\
\hline Ascorbate and aldarate metabolism & UGT2A3, UGT2B I5, ALDH3A2 & 0.07 & 57.1 \\
\hline Drug metabolism & GSTA I, GSTA2, UGT2A3, UGT2B I5, ALDH3AI & 0.07 & 59.4 \\
\hline Pathways in cancer & $\begin{array}{l}\text { IL6, FGFR3, IL8, FOXOI, KITLG, CDHI, FZD7, JUP, CDKNIA, } \\
\text { RASSF5, LAMC3, JUN, RACI, LAMC2 }\end{array}$ & 0.07 & 60.2 \\
\hline Bladder cancer & CDKNIA, FGFR3, IL8, CDHI & 0.09 & 67.9 \\
\hline Starch and sucrose metabolism & PYGL, GK, UGT2A3, UGT2B 15 & 0.09 & 67.9 \\
\hline D-glutamine and D-glutamate metabolism & GLS & 0.09 & 70.8 \\
\hline \multicolumn{4}{|c|}{ Trastuzumab-treated compared with pertuzumab treated (I 19 probes) } \\
\hline Axon guidance & ABLIMI, SRGAP3, SEMA4C & 0.05 & 38.9 \\
\hline
\end{tabular}

Abbreviations: FDR = false discovery rate; KEGG $=$ Kyoto Encyclopaedia of Genes and Genomes.

A
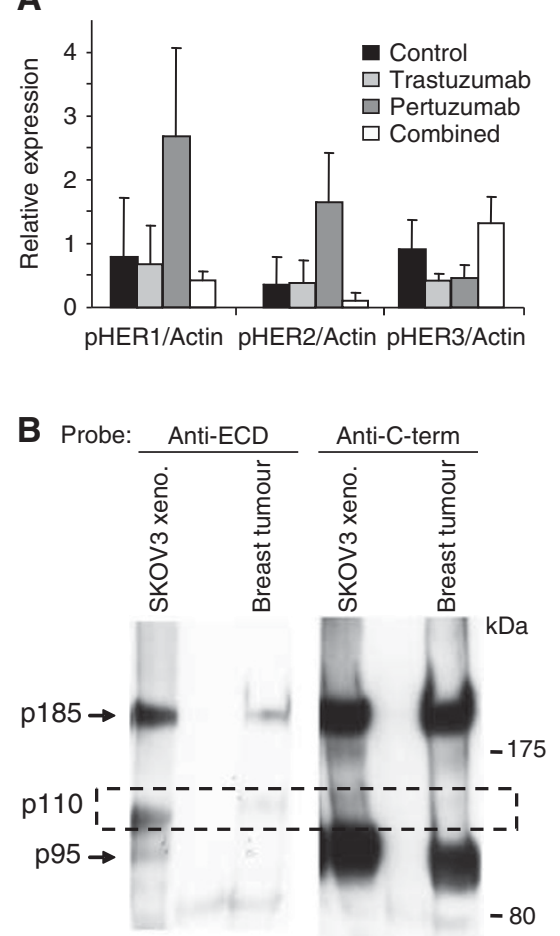

C

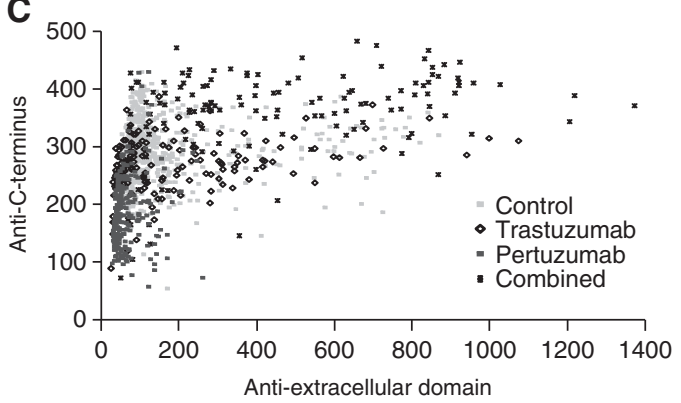

D

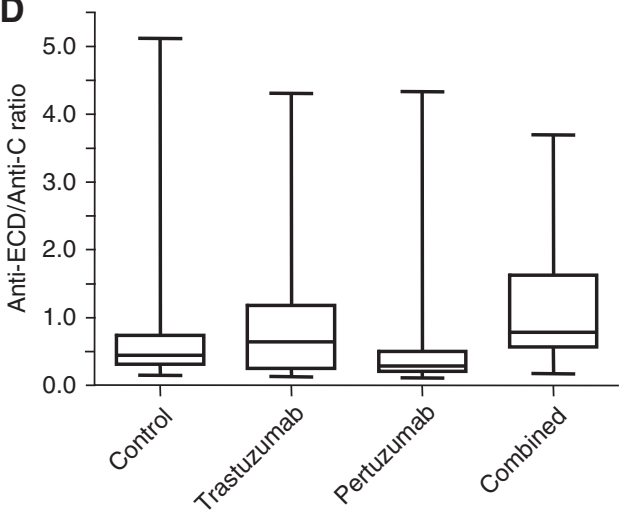

Figure 2 HER receptor signalling. Phosphorylation of human epidermal growth factor receptors (HERs) I, 2 and 3 after I 4 days of therapy and control as detected by western blotting (A). Anti-HER2 C-terminal western blotting using day I 4 tumours showed two bands, p I 85 and p95, but anti-extracellular domain (ECD) of HER2 blotting revealed another band ( $\mathrm{pl} / 0)$ consistent with the ECD produced by shedding from full-length HER2 (B). Anti-ECD and anti-C-terminal antibodies after 14 days in whole tissue sections using quantitative immunofluorescence $(\mathbf{C})$. The ECD to $C$-terminus ratio (D) was increased in trastuzumab-treated groups (alone or combined), suggesting that increased shedding inhibited by trastuzumab. 
HER1, but not HER3 (Figure 2A and B) consistent with in-vitro studies (Le et al, 2005a; Lee-Hoeflich et al, 2008). Although it is currently unclear whether increased phosphorylation activates downstream signalling, this might be one of the reasons why the combination is more effective because trastuzumab reduced the phosphorylation. It is also consistent with the mechanism of pertuzumab shown by previous studies that it does not block signals from HER1 homodimers or HER1-HER3 heterodimers (Burris et al, 2005; Vegran et al, 2009). There were both similarities and differences between the genes that were differentially expressed in our study and those highlighted by a recent gene expression study (Ghosh et al, 2011) of HER2 homodimers and HER2/HER1 or HER2/HER3 heterodimers in HER2-expressing MCF10A cells (Supplementary Figure 2C and D), which may indicate cell- or disease-specific signalling. Anti-HER2 C-terminal blotting using day 14 tumours showed two bands, p185 and p95 (Figure 2B). The p95 band is well described in breast cancers and hypothesised to contribute to trastuzumab/pertuzumab resistance, but in ovarian cancer little is known. Anti-ECD of HER2 blotting revealed another band ( $\mathrm{p} 110)$ consistent with the ECD produced by shedding of full-length HER2 (Figure 2B). This observation led us to examine HER2 population expression by both anti-ECD and anti-C-terminal antibodies on the 14 day whole tissue sections using quantitative immunofluorescence (Figure 2C). The ECD to C-terminus ratio (Figure 2D) was increased in trastuzumab-treated groups (alone or combined), suggesting that increased shedding is inhibited by trastuzumab, which is consistent with one of the proposed mechanisms of action of trastuzumab (Badache and Hynes, 2004). Two pathways thought to be involved in the response to the HER2 inhibitors, ERK and Akt were assessed by phosphoprotein assay. Pertuzumab alone reduced expression of pAkt, while both antibodies and the combination reduced expression of pERK after 4 days (Figure $3 \mathrm{~A}$ ).

\section{Time-course analysis of trastuzumab and pertuzumab treatment at protein level}

Tissue microarrays were constructed from four cores from three different SKOV3 xenografts to analyse changes in protein level at five time points from the beginning of the treatment (days 1, 2, 4, 7 and 14). Quantitation of pAkt and pERK using AQUA quantitative immunofluorescence confirmed the immunohistochemical observations (Figure 3). The levels of Ki67, phospho-histone H3 and cleaved caspase 3 were measured to assess changes in proliferation, cell division and apoptosis. Expression of the markers was somewhat variable across the time points, but was largely consistent using immunohistochemistry (Figure 4). The changes in Ki67 and phospho-histone $\mathrm{H} 3$ expression upon treatment of SKOV3 xenografts were not significant; however, combination treatment with trastuzumab and pertuzumab resulted in more apoptotic cells during the first few days of therapy, as seen by an increase in cleaved caspase 3 (Figure 4). The gene expression level of cyclin-dependent kinase (CDK) inhibitor $1 \mathrm{~A}$ (CDKN1A/p21) was upregulated by all treatments (Figures 1 and 4). The level of p21 protein appeared to be greatest after 7 days of pertuzumab therapy compared with trastuzumab or combination (Figure 5). The protein level of CDK-inhibitor 1B (p27/CDKN1B) was significantly increased in response to both trastuzumab and the combination treatment (Figure 4), but the gene expression level measured by two Illumina probes was unchanged after 4 days.
A

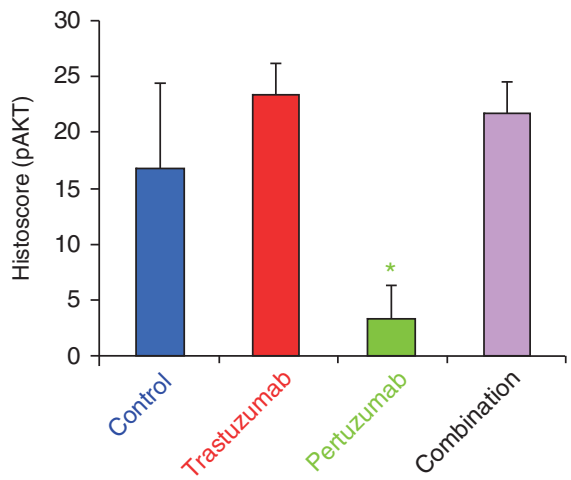

C

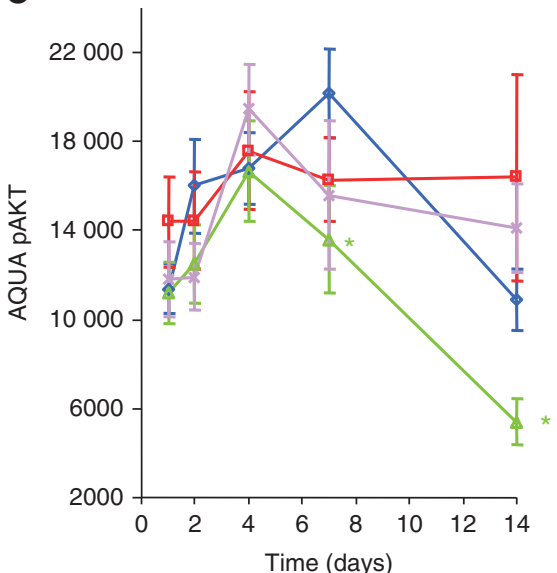

B

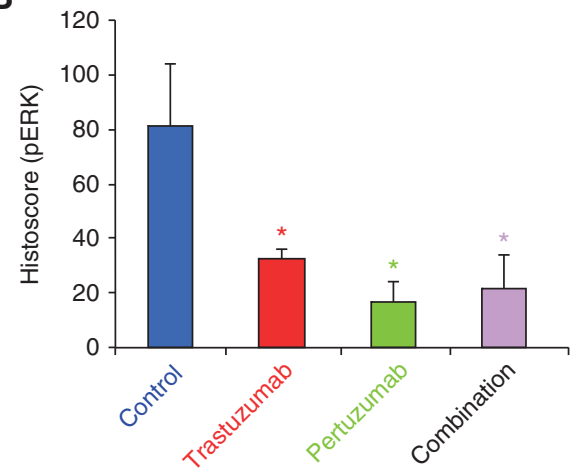

D

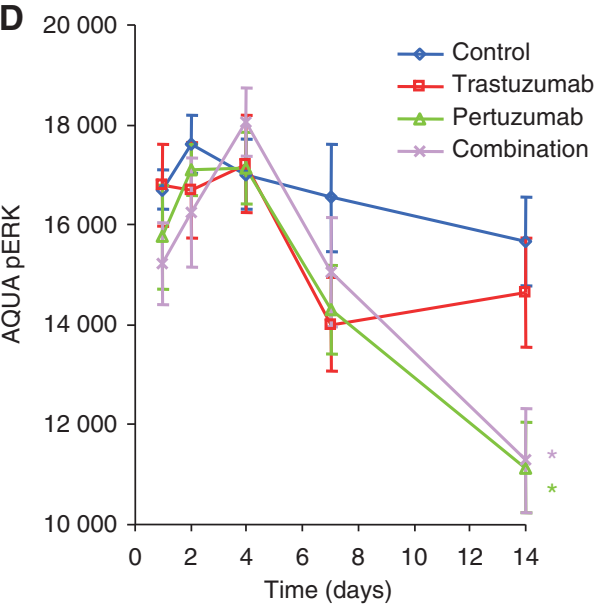

Figure 3 Pertuzumab reduces phospho-AKT, but phospho-ERK is reduced by either drug or combination. Assessment of phospho-AKT (A) and phospho-ERK (B) in SKOV3 xenograft tumours after 7 days using immunohistochemistry. Assessment of phospho-AKT (C) and phospho-ERK (D) in SKOV3 xenograft tumours across a time course using AQUA quantitative immunofluorescence. $* P<0.05$ Student's $t$-test of treatment relative to control. 

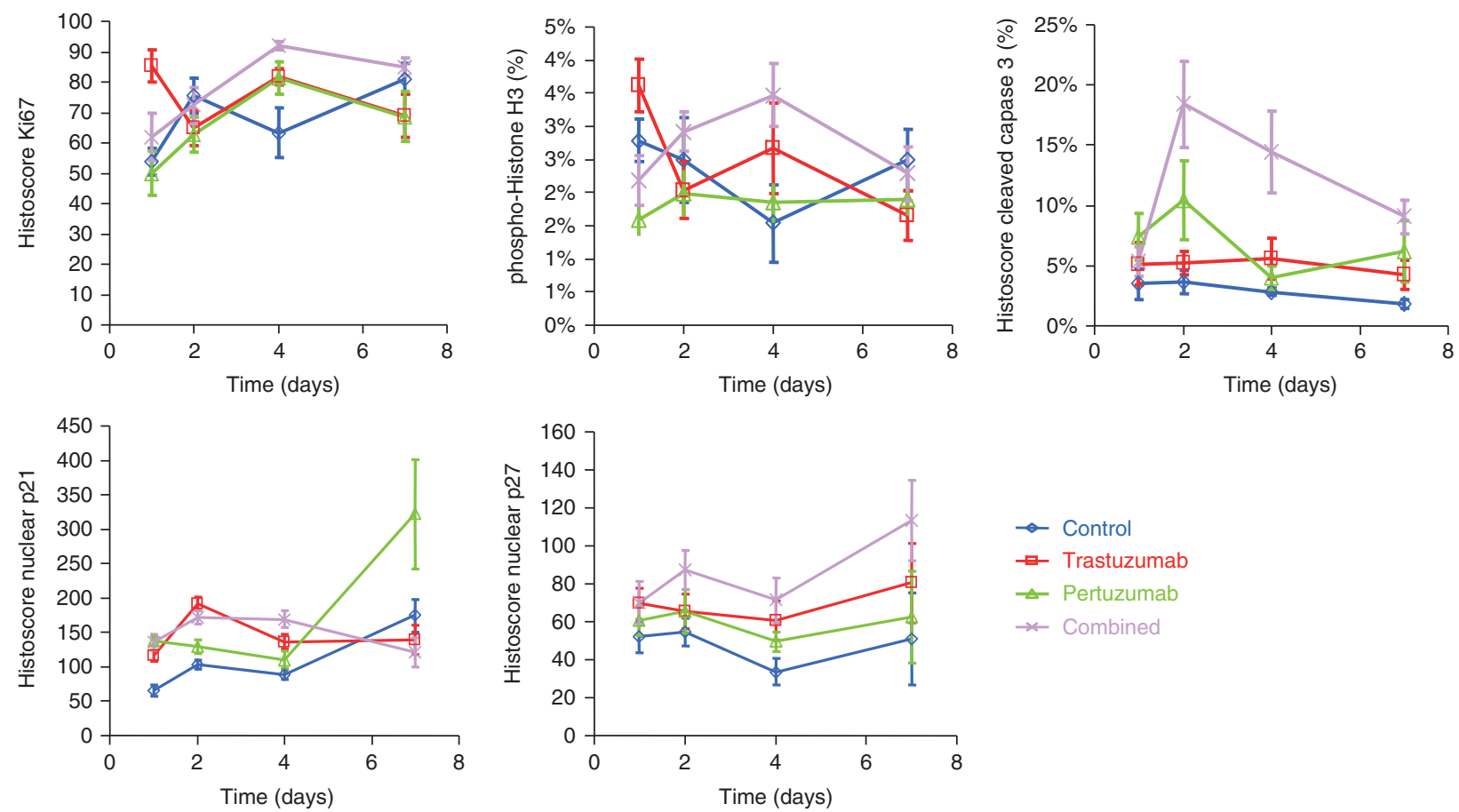

Figure 4 Effect of single or combination therapy on proliferation, cell cycle, apoptosis and protein markers over time. Total and phosphoprotein levels were determined by immunohistochemistry of TMAs for Ki67, phopho-histone H3, cleaved caspase 3, p2I and p27. See Supplementary Figure 3 for comparable AQUA quantitative immunofluorescence results.
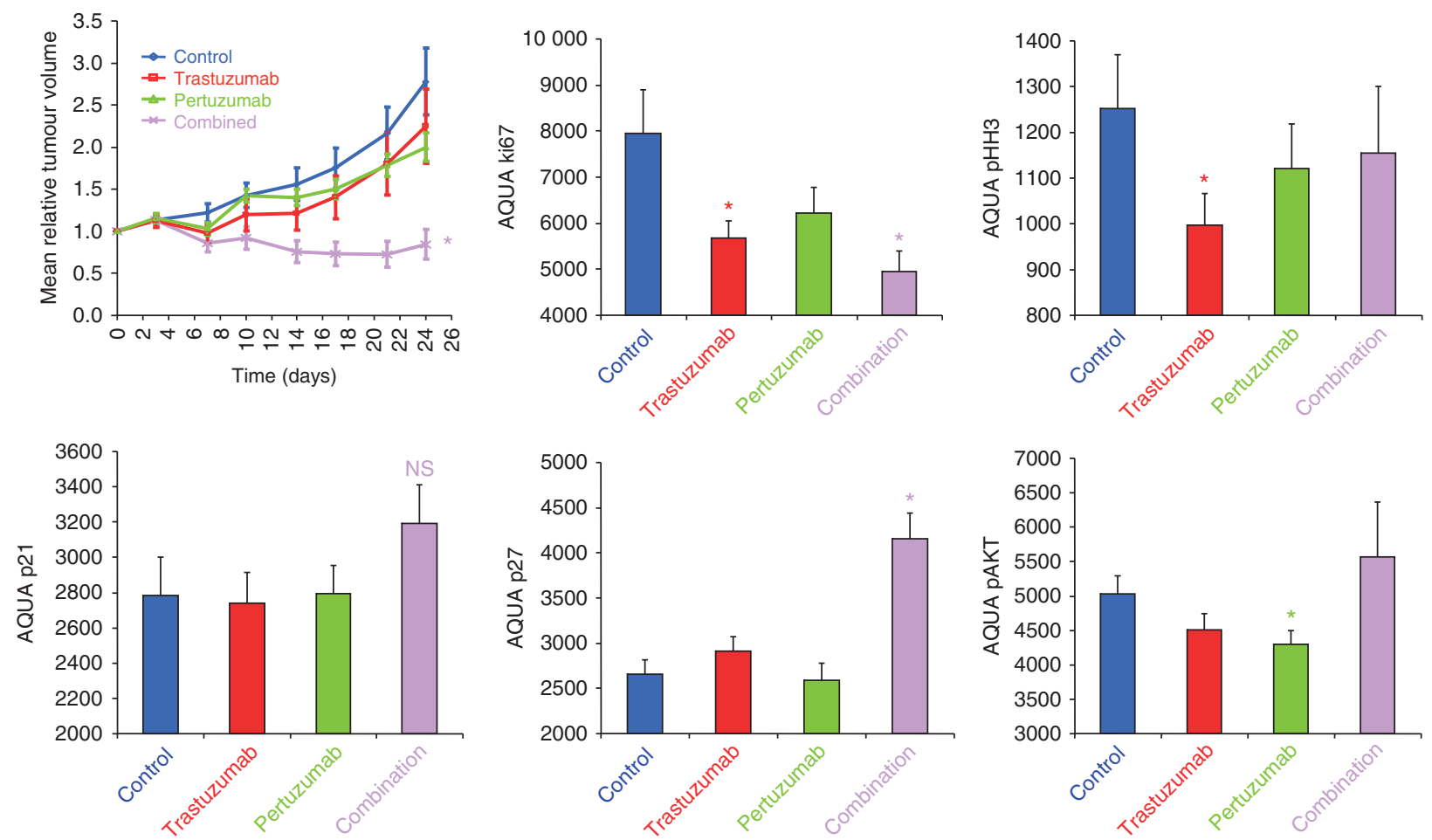

Figure 5 Combination therapy is more effective than either agent alone in a primary tumour. The primary ovarian xenograft HOX424 shows significantly greater growth inhibition to combined trastuzumab and pertuzumab treatment than to either agent alone. Total and phosphoprotein levels were determined by AQUA quantitative immunofluorescence of TMAs for Ki67, phospho-histone H3, p2I, p27 and phospho-AKT after 24 days. *P $<0.05$ Student's t-test of treatment relative to control. 


\section{Differential response to combination therapy in a panel of} primary ovarian cancer xenografts

We previously established that response to combined antibody therapy (trastuzumab plus pertuzumab) was variable across a panel of five xenografts derived from primary ovarian tumours or ascites (Faratian et al, 2011). The xenograft model (HOX 424) with the highest HER2 protein expression and the biggest increase in HER3 on treatment had a complete response to treatment with the combined antibodies, two xenograft models showed a partial response (HOX516 and HOX486) and two were unaffected by treatment (HOX493 and OV1002) (Faratian et al, 2011). Human epidermal growth factor receptor 2 FISH was undertaken on these five xenografts together with the SKOV3 model and HER2 gene amplification was observed in the two responsive xenograft models, HOX 424 and SKOV-3, but not in the other four xenograft models (Supplementary Figure 3). HOX 424 xenografts demonstrated a 7.8-fold amplification of HER2 while SKOV3 was 2.2-fold amplified, consistent with previous reports (Rhodes et al, 2002). Expression of EGFR (HER1) was also investigated, but showed no consistent change on treatment (Figure 6). These results are consistent with the view that this combination of antibodies is likely to be most effective in HER2-amplified cancers.

To further understand the effects of the two agents, HOX424 was subjected to both antibody treatments alone and in combination. We found that growth of the HOX424 xenograft tumours was significantly reduced when treated with the combination therapy, but not by either agent alone (Figure 5). There was significant reduction in Ki67 in the trastuzumab and (greater) in the combination treated tumours. Phospho-histone $\mathrm{H} 3$ was also reduced, most greatly in the trastuzumab-treated tumours (Figure 5). Levels of p21 and p27 were only increased with the combination, perhaps reflecting the synergistic effect of the agents. As in the SKOV3 xenografts, pertuzumab alone significantly reduced expression of pAkt (Figure 5). The level of pERK was unchanged by either treatment alone or in combination (data not shown); however, this may have been due to the rather late single time point at 24 days.

To ascertain the further applicability of our results, we examined the effect of trastuzumab and pertuzumab combination therapy on proliferation, apoptosis, cell division and cell cycle across all five xenografts. Quantification by immunohistochemistry and AQUA quantitative immunofluorescence methods was highly consistent. Ki67 was found to be markedly decreased in HOX424 and HOX516; these tumours also showed decreases in cleaved caspase 3. The mean level of phospho-histone $\mathrm{H} 3$ was increased in OV1002, but decreased in HOX424 (Figure 6). In contrast to the increase in CDK1NA gene expression in SKOV3 cells after 4 days (Figures 1 and 2), the nuclear protein expression of p21 was reduced in HOX424 and HOX486 following the combination therapy (Figure 6). The level of p27 was clearly increased in the three ovarian xenografts models that responded well to combination treatment, although HOX516 was unchanged that may be consistent with only a tempory reduction in tumour volume at day 4, before increasing by day 7 (Figure 6). Levels of pAKT and pERK were not significantly changed at day 7 .
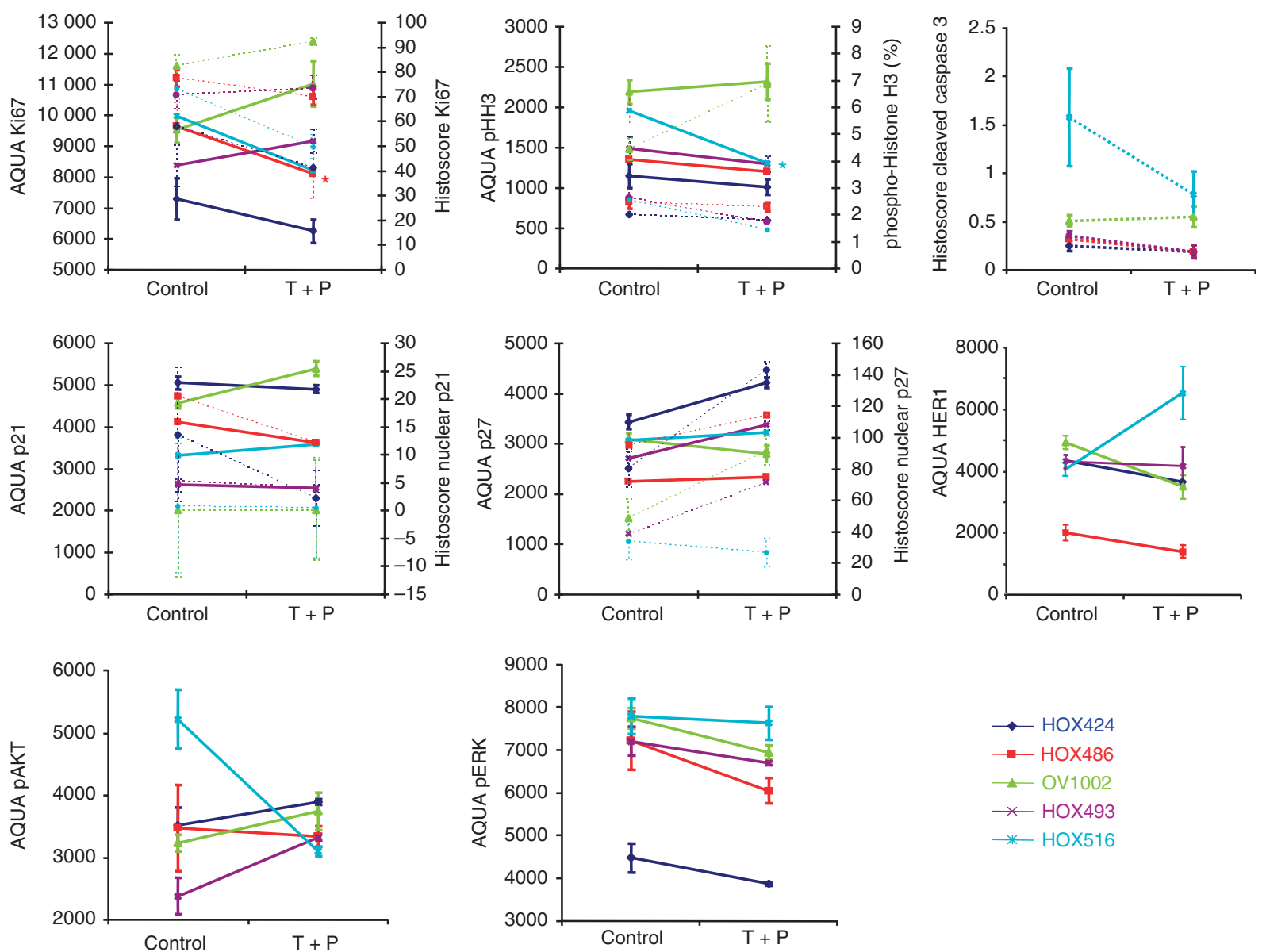

Figure 6 Differential responses to combination therapy in a panel of primary ovarian xenografts. Five human xenografts grown from material obtained primary ovarian cancer patients were treated with the trastuzumab plus pertuzumab combination. HOX 424 displayed a complete growth response, $\mathrm{HOX} 516$ and $\mathrm{HOX} 486$ show a minor response and HOX493 and OVI002 were unresponsive. Xenografts were collected on day 7. Mean values ( \pm s.e.) of at least four tumours/group are shown. Dashed lines show changes for immunohistochemistry, solid lines for AQUA quantitative immunofluorescence. 


\section{DISCUSSION}

Although trastuzumab and pertuzumab target different epitopes of HER2 (Badache and Hynes, 2004) and have differing modes of action (Franklin et al, 2004; Spector and Blackwell, 2009), downstream signalling and the molecular response to anti-HER2 antibodies has not previously been clearly characterised in any cancer setting in vivo. In this study, for the first time we comprehensively examine the molecular response to two important anticancer agents alone or in combination, both in terms of the transcriptome and key markers of established pathways, proliferation, apoptosis, cell division and cell cycle at the protein level. Induction of p27 has previously been described as one of the key modes of action of HER2-targeting antibodies in breast cancer (Le et al, 2005b), with an increase thought to cause proliferating cells to exit the cell cycle and induce apoptosis. Downregulation of p27 has been associated with trastuzumab resistance in breast cancer cells (Nahta et al, 2004b). The level of p27 expression in SKOV3 xenografts in this study was primarily increased after combination treatment. Gene expression level of p27 was apparently not increased, but the level of p21 was significantly higher following all treatments. Cyclin G2 has previously been shown to be upregulated following the trastuzumab treatment in BT474 cells in vitro and in vivo (Le et al, 2007); it was also upregulated by trastuzumab in this study, but was downregulated by pertuzumab (Supplementary Figure 2A). The growth arrest response gene $G A D D 45 A$ was increased by all treatments and is known to be induced following the growth arrest conditions, resulting in cell-cycle arrest (Jiang et al, 2003).

Gene expression profiling of SKBR3 and BT474 breast cancer cells in vitro has suggested that trastuzumab downregulates genes of the cell cycle, cell growth, cell maintenance, and chromatin structure (Le et al, 2005a). Neoadjuvant trastuzumab treatment has previously been shown to induce apoptosis in primary breast cancers (Mohsin et al, 2005). However apoptosis-related genes were not able to distinguish between responding and nonresponding trastuzumab-docetaxel breast tumours (Vegran et al, 2009). A study of treatment with pertuzumab and/or trastuzumab resulted in a reduced fraction of proliferating cells, prolongation of G1 phase and a great increase in quiescent BT474 cells with either agent, but did not induce an appreciable amount of apoptosis in either BT474 or SKBR3 cells (Brockhoff et al, 2007). KLK11 was among the highest upregulated genes for the combination therapy and has previously been found to predict unfavourable prognosis in ovarian cancer (Shigemasa et al, 2004).

Cytokines and chemokines have a lead role in cancer-related inflammation, promoting tumour cell survival, proliferation and metastasis (Germano et al, 2008). In this study, pertuzumab treatment appeared to stimulate an inflammatory response, whereas trastuzumab or the combination treatment suppressed the process, which is more consistent with the immunoreactive actions previously noted through ADCC (Arnould et al, 2006). A number of laminins and keratins were differentially expressed upon treatment. These are known to promote cell adhesion, migration, protease activity, proliferation, tumour growth, angiogenesis and metastasis (Engbring and Kleinman, 2003).

Trastuzumab and pertuzumab combination therapy has been shown to provide enhanced antitumour activity in non-small cell lung (Scheuer et al, 2009), breast (Baselga et al, 2012) and now in ovarian cancer xenografts; however, it is not entirely clear how these drugs may complement each other. The expression of genes that had discordant expression between the two agents correlated much more strongly between the trastuzumab and the combination than between pertuzumab and combination, demonstrating that the molecular response to trastuzumab dominates, consistent with the changes in tumour volume and apoptosis.

The synergistic action of trastuzumab and pertuzumab combination treatment was previously shown in vitro to be mediated by enhanced disruption of receptor dimers, leading to increased apoptosis (Nahta et al, 2004a). Recent in-silico simulations suggest that the clinical synergism observed for the two antibodies arises partly from enhanced affinity that originates in cooperative interactions between the two antibodies when they are colocalised on HER2 and effectively 'clamp' it; this may inhibit dimerisation and possibly higher oligomerisations with neighbouring receptors (Fuentes et al, 2011). Another explanation for the synergistic activity of trastuzumab and pertuzumab is the inhibition of two different HER2 activation mechanisms; while trastuzumab inhibits the proteolytic shedding of HER2 ECD, which produces the constitutively active truncated form p95HER2 (Molina et al, 2001), and ligand-independent formation of HER2:HER3 heterodimers (Junttila et al, 2009), pertuzumab inhibits ligand-activated HER2 heterodimers (Agus et al, 2002; Franklin et al, 2004; Junttila et al, 2009).

Phosphorylated p44/p42 MAPK (pERK1/2) was unaltered, while the combination of trastuzumab and pertuzumab reduced levels of active pAkt to a greater degree $v s$ either agent alone in BT474 cells (Nahta et al, 2004a). However, in the current study of ovarian tumours in vivo, pERK was reduced by all treatments after 7 days and pAKT was reduced by pertuzumab alone, but not by trastuzumab or the combination. It has recently been shown that the response of HER2-amplified AU565, SKBR3 and HCC1569 cells to these anti-HER2 agents are highly dependent on the 3D environment and this has a substantial impact on downstream signalling (Weigelt et al, 2010), which may account for some of the differences seen in our results and previous in-vitro expression profiling studies. Comparison of $3 \mathrm{D}$ with $2 \mathrm{D}$ culture studies demonstrated a shift in dependency from Akt to ERK dependency in $3 \mathrm{D}$ with a consequent enhancement of growth response to trastuzumab (Weigelt et al, 2010).

While changes in gene expression can be very useful in highlighting the genes and pathways induced by the agents, they were limited to a 'snapshot' at day 4 following the initiation of treatment. We recently showed that the response to tamoxifen in breast cancer xenografts is a highly dynamic process (Taylor et al, 2010). While further time points would be useful, they obviously involve the collection of much more material. The protein changes measured in this study hint at the complex dynamics of the response to these agents (Figure 3). Some of the primary ovarian xenografts demonstrate similar responses to combination therapy as the SKOV3 cells, although there was significant variation, consistent with the molecular heterogeneity of ovarian tumours (Marquez et al, 2005; Zorn et al, 2005) and demonstrating the need to identify robust biomarkers of response. There was distinct morphological heterogeneity within and between xenografts following the treatment, with clear cell areas markedly reduced following the treatment with trastuzumab and significantly reduced after combination therapy-treated tumours (Faratian et al, 2011). The molecular response to letrozole in ER + breast tumours was found to be homogeneous for responders and heterogeneous for non-responders (Miller et al, 2009). Whether the differences in molecular response noted in this study are disease specific or due to in-vivo rather than in-vitro analysis is not clear and deserves further investigation. It would be very interesting to compare gene expression changes with the different antibodies and combination in a neoadjuvant 'window study'; however, it is simply not possible to expose the same tumour to different regimens as it is with our in-vivo approach. The intratumoural heterogeneity of HER2 expression may also be a consideration. Heterogeneity of HER2 expression has been observed in some gastric cancer specimens (Grabsch et al, 2010) and mucinous ovarian cancer (McAlpine et al, 2009).

The results in the present study support the hypothesis that trastuzumab and pertuzumab inhibit different molecular pathways implied by different HER2 activation mechanisms. In SKOV3 cells, mechanisms sensitive to trastuzumab inhibition like HER2 ECD 
shedding seem to be prevalent (Figure 2B). This is reflected both in the more potent growth inhibition by trastuzumab compared with pertuzumab monotherapy, as well as by the fact that the molecular changes found in combination treatment are dominated by trastuzumab. Accordingly, the sensitivity of individual tumours to trastuzumab and pertuzumab treatment, respectively, may depend on the expression of HER-family receptors, their ligands, receptor activating proteases and alternative signalling pathways. Furthermore, upregulation of HER2 heterodimerisation partners like HER3 and HER-family ligands like neuregulin during trastuzumab treatment of HER2-positive tumours suggests the use of combination treatment early on. Since the combination is effective both in a serous and in a mixed clear cell/endometrioid models that have in common amplification of HER2 expression, our results would suggest that this combination of antibodies is likely to be most effective in high HER2 expressing ovarian cancers, irrespective of histology.

In conclusion, a number of previously characterised signalling pathways are both commonly and distinctly affected by two agents that target alternative domains of HER2 in ovarian tumours in vivo. The molecular response to combination treatment exhibited both common and distinct aspects of single agent

\section{REFERENCES}

Agus DB, Akita RW, Fox WD, Lewis GD, Higgins B, Pisacane PI, Lofgren JA, Tindell C, Evans DP, Maiese K, Scher HI, Sliwkowski MX (2002) Targeting ligand-activated ErbB2 signaling inhibits breast and prostate tumor growth. Cancer Cell 2: 127-137

Aitken SJ, Thomas JS, Langdon SP, Harrison DJ, Faratian D (2010) Quantitative analysis of changes in ER, PR and HER2 expression in primary breast cancer and paired nodal metastases. Ann Oncol 21: 1254-1261

Arnould L, Gelly M, Penault-Llorca F, Benoit L, Bonnetain F, Migeon C, Cabaret V, Fermeaux V, Bertheau P, Garnier J, Jeannin JF, Coudert B (2006) Trastuzumab-based treatment of HER2-positive breast cancer: an antibody-dependent cellular cytotoxicity mechanism? Br J Cancer 94: 259-267

Badache A, Hynes NE (2004) A new therapeutic antibody masks ErbB2 to its partners. Cancer Cell 5: 299-301

Banerjee S, Gore M (2009) The future of targeted therapies in ovarian cancer. Oncologist 14: 706-716

Baselga J, Cortes J, Kim SB, Im SA, Hegg R, Im YH, Roman L, Pedrini JL, Pienkowski T, Knott A, Clark E, Benyunes MC, Ross G, Swain SM (2012) Pertuzumab plus trastuzumab plus docetaxel for metastatic breast cancer. N Engl J Med 366: 109-119

Bookman MA, Darcy KM, Clarke-Pearson D, Boothby RA, Horowitz IR (2003) Evaluation of monoclonal humanized anti-HER2 antibody, trastuzumab, in patients with recurrent or refractory ovarian or primary peritoneal carcinoma with overexpression of HER2: a phase II trial of the Gynecologic Oncology Group. J Clin Oncol 21: 283-290

Brockhoff G, Heckel B, Schmidt-Bruecken E, Plander M, Hofstaedter F, Vollmann A, Diermeier S (2007) Differential impact of Cetuximab, Pertuzumab and Trastuzumab on BT474 and SK-BR-3 breast cancer cell proliferation. Cell Prolif 40: 488-507

Burris 3rd HA, Hurwitz HI, Dees EC, Dowlati A, Blackwell KL, O'Neil B, Marcom PK, Ellis MJ, Overmoyer B, Jones SF, Harris JL, Smith DA, Koch KM, Stead A, Mangum S, Spector NL (2005) Phase I safety, pharmacokinetics, and clinical activity study of lapatinib (GW572016), a reversible dual inhibitor of epidermal growth factor receptor tyrosine kinases, in heavily pretreated patients with metastatic carcinomas. J Clin Oncol 23: 5305-5313

Camp RL, Chung GG, Rimm DL (2002) Automated subcellular localization and quantification of protein expression in tissue microarrays. Nat Med 8: $1323-1327$

Clynes RA, Towers TL, Presta LG, Ravetch JV (2000) Inhibitory Fc receptors modulate in vivo cytotoxicity against tumor targets. Nat Med 6: 443-446

Eisen MB, Spellman PT, Brown PO, Botstein D (1998) Cluster analysis and display of genome-wide expression patterns. Proc Natl Acad Sci USA 95: 14863-14868

Engbring JA, Kleinman HK (2003) The basement membrane matrix in malignancy. J Pathol 200: 465-470 therapy, although overall was more similar to that of trastuzumab alone.

\section{ACKNOWLEDGEMENTS}

We would like to thank Kevin Kinch for help during the early phase of this work. The Wellcome Trust Clinical Research Facility in Edinburgh are thanked for processing the Illumina BeadChips. We thank the University of Tsukuba International Liaison Project (FY2007) for support for Y Nagumo, the Dr Saal van Zwanenberg Foundation for support of AJM Zweemer, and to Roche Diagnostics, the Charon Fund, Breakthrough Breast Cancer, and Scottish Funding Council for support of this work.

\section{Conflict of interest}

Dr Hasmann is an employee of Roche and some support for this study was provided by Roche.

Supplementary Information accompanies the paper on British Journal of Cancer website (http://www.nature.com/bjc)
Faratian D, Zweemer AJM, Nagumo Y, Sims AH, Muir M, Dodds M, Hasmann M, Harrison DJ, Langdon SP (2011) Trastuzumab and pertuzumab produce changes in morphology and estrogen receptor signaling in ovarian cancer xenografts revealing new treatment strategies. Clin Cancer Res 17: 4450-4460

Franklin MC, Carey KD, Vajdos FF, Leahy DJ, de Vos AM, Sliwkowski MX (2004) Insights into ErbB signaling from the structure of the ErbB2pertuzumab complex. Cancer Cell 5: 317-328

Fuentes G, Scaltriti M, Baselga J, Verma CS (2011) Synergy between trastuzumab and pertuzumab for human epidermal growth factor 2 (Her2) from colocalization: an in silico based mechanism. Breast Cancer Res 13: R54

Germano G, Allavena P, Mantovani A (2008) Cytokines as a key component of cancer-related inflammation. Cytokine 43: 374-379

Ghosh R, Narasanna A, Wang SE, Liu S, Chakrabarty A, Balko JM, Gonzalez-Angulo AM, Mills GB, Penuel E, Winslow J, Sperinde J, Dua R, Pidaparthi S, Mukherjee A, Leitzel K, Kostler WJ, Lipton A, Bates M, Arteaga CL (2011) Trastuzumab has preferential activity against breast cancers driven by HER2 homodimers. Cancer Res 71: 1871-1882

Gordon MS, Matei D, Aghajanian C, Matulonis UA, Brewer M, Fleming GF Hainsworth JD, Garcia AA, Pegram MD, Schilder RJ, Cohn DE, Roman L, Derynck MK, Ng K, Lyons B, Allison DE, Eberhard DA, Pham TQ, Dere RC, Karlan BY (2006) Clinical activity of pertuzumab (rhuMAb 2C4), a HER dimerization inhibitor, in advanced ovarian cancer: potential predictive relationship with tumor HER2 activation status. J Clin Oncol 24: 4324-4332

Grabsch H, Sivakumar S, Gray S, Gabbert HE, Muller W (2010) HER2 expression in gastric cancer: Rare, heterogeneous and of no prognostic value-conclusions from 924 cases of two independent series. Cell Oncol 32: $57-65$

Huang da W, Sherman BT, Lempicki RA (2009) Systematic and integrative analysis of large gene lists using DAVID bioinformatics resources. Nat Protoc 4: 44-57

Jiang F, Li P, Fornace Jr AJ, Nicosia SV, Bai W (2003) G2/M arrest by 1,25dihydroxyvitamin D3 in ovarian cancer cells mediated through the induction of GADD45 via an exonic enhancer. J Biol Chem 278: 48030-48040

Junttila TT, Akita RW, Parsons K, Fields C, Lewis Phillips GD, Friedman LS, Sampath D, Sliwkowski MX (2009) Ligand-independent HER2/HER3/ PI3K complex is disrupted by trastuzumab and is effectively inhibited by the PI3K inhibitor GDC-0941. Cancer Cell 15: 429-440

Kaye SB, Poole CJ, Bidzinski M, Gianni L, Gorbunova V, Novikova E, Strauss A, McNally VA, Ross G, Vergote I (2008) A randomised phase II study evaluating the combination of carboplatin-based chemotherapy with pertuzumab (P) versus carboplatin-based therapy alone in patients with relapsed, platinum sensitive ovarian cancer. J Clin Oncol 26: 5520 
Kononen J, Bubendorf L, Kallioniemi A, Barlund M, Schraml P, Leighton S, Torhorst J, Mihatsch MJ, Sauter G, Kallioniemi OP (1998) Tissue microarrays for high-throughput molecular profiling of tumor specimens. Nat Med 4: 844-847

Le XF, Arachchige-Don AS, Mao W, Horne MC, Bast Jr RC (2007) Roles of human epidermal growth factor receptor 2, c-jun NH2-terminal kinase, phosphoinositide 3-kinase, and p70 S6 kinase pathways in regulation of cyclin G2 expression in human breast cancer cells. Mol Cancer Ther 6: 2843-2857

Le XF, Lammayot A, Gold D, Lu Y, Mao W, Chang T, Patel A, Mills GB, Bast Jr RC (2005a) Genes affecting the cell cycle, growth, maintenance, and drug sensitivity are preferentially regulated by anti-HER2 antibody through phosphatidylinositol 3-kinase-AKT signaling. J Biol Chem 280: 2092-2104

Le XF, Pruefer F, Bast Jr RC (2005b) HER2-targeting antibodies modulate the cyclin-dependent kinase inhibitor p27Kip1 via multiple signaling pathways. Cell Cycle 4: 87-95

Lee-Hoeflich ST, Crocker L, Yao E, Pham T, Munroe X, Hoeflich KP, Sliwkowski MX, Stern HM (2008) A central role for HER3 in HER2amplified breast cancer: implications for targeted therapy. Cancer Res 68: 5878-5887

Makhija S, Amler LC, Glenn D, Ueland FR, Gold MA, Dizon DS, Paton V, Lin CY, Januario T, Ng K, Strauss A, Kelsey S, Sliwkowski MX, Matulonis U (2010) Clinical activity of gemcitabine plus pertuzumab in platinumresistant ovarian cancer, fallopian tube cancer, or primary peritoneal cancer. J Clin Oncol 28: 1215-1223

Marquez RT, Baggerly KA, Patterson AP, Liu J, Broaddus R, Frumovitz M, Atkinson EN, Smith DI, Hartmann L, Fishman D, Berchuck A, Whitaker R, Gershenson DM, Mills GB, Bast Jr RC, Lu KH (2005) Patterns of gene expression in different histotypes of epithelial ovarian cancer correlate with those in normal fallopian tube, endometrium, and colon. Clin Cancer Res 11: 6116-6126

McAlpine JN, Wiegand KC, Vang R, Ronnett BM, Adamiak A, Kobel M, Kalloger SE, Swenerton KD, Huntsman DG, Gilks CB, Miller DM (2009) HER2 overexpression and amplification is present in a subset of ovarian mucinous carcinomas and can be targeted with trastuzumab therapy. BMC Cancer 9: 433

Miller WR, Larionov A, Renshaw L, Anderson TJ, Walker JR, Krause A, Sing T, Evans DB, Dixon JM (2009) Gene expression profiles differentiating between breast cancers clinically responsive or resistant to letrozole. J Clin Oncol 27: 1382-1387

Mohsin SK, Weiss HL, Gutierrez MC, Chamness GC, Schiff R, Digiovanna MP, Wang CX, Hilsenbeck SG, Osborne CK, Allred DC, Elledge R, Chang JC (2005) Neoadjuvant trastuzumab induces apoptosis in primary breast cancers. J Clin Oncol 23: 2460-2468

Molina MA, Codony-Servat J, Albanell J, Rojo F, Arribas J, Baselga J (2001) Trastuzumab (herceptin), a humanized anti-Her2 receptor monoclonal antibody, inhibits basal and activated Her2 ectodomain cleavage in breast cancer cells. Cancer Res 61: 4744-4749

Mullen P, Cameron DA, Hasmann M, Smyth JF, Langdon SP (2007) Sensitivity to pertuzumab (2C4) in ovarian cancer models: cross-talk with estrogen receptor signaling. Mol Cancer Ther 6: 93-100
Nahta R, Hung MC, Esteva FJ (2004a) The HER-2-targeting antibodies trastuzumab and pertuzumab synergistically inhibit the survival of breast cancer cells. Cancer Res 64: 2343-2346

Nahta R, Takahashi T, Ueno NT, Hung MC, Esteva FJ (2004b) P27(kip1) down-regulation is associated with trastuzumab resistance in breast cancer cells. Cancer Res 64: 3981-3986

Rhodes A, Jasani B, Couturier J, McKinley MJ, Morgan JM, Dodson AR, Navabi H, Miller KD, Balaton AJ (2002) A formalin-fixed, paraffin-processed cell line standard for quality control of immunohistochemical assay of HER-2/neu expression in breast cancer. Am J Clin Pathol 117: 81-89

Rivkin SE, Muller C, Iriarte D, Arthur J, Canoy A, Reid H (2008) Phase I/II lapatinib plus carboplatin and paclitaxel in stage III or IV relapsed ovarian cancer patients. J Clin Oncol 26: 5556

Scheuer W, Friess T, Burtscher H, Bossenmaier B, Endl J, Hasmann M (2009) Strongly enhanced antitumor activity of trastuzumab and pertuzumab combination treatment on HER2-positive human xenograft tumor models. Cancer Res 69: 9330-9336

Serrano-Olvera A, Duenas-Gonzalez A, Gallardo-Rincon D, Candelaria M, De la Garza-Salazar J (2006) Prognostic, predictive and therapeutic implications of HER2 in invasive epithelial ovarian cancer. Cancer Treat Rev 32: $180-190$

Shigemasa K, Gu L, Tanimoto H, O'Brien TJ, Ohama K (2004) Human kallikrein gene 11 (KLK11) mRNA overexpression is associated with poor prognosis in patients with epithelial ovarian cancer. Clin Cancer Res 10: $2766-2770$

Spector NL, Blackwell KL (2009) Understanding the mechanisms behind trastuzumab therapy for human epidermal growth factor receptor 2-positive breast cancer. J Clin Oncol 27: 5838-5847

Takai N, Jain A, Kawamata N, Popoviciu LM, Said JW, Whittaker S, Miyakawa I, Agus DB, Koeffler HP (2005) 2C4, a monoclonal antibody against HER2, disrupts the HER kinase signaling pathway and inhibits ovarian carcinoma cell growth. Cancer 104: 2701-2708

Taylor K, Sims AH, Liang L, Faratian D, Muir M, Walker G, Kuske B, Dixon JM, Harrison D, Cameron DA, Langdon SP (2010) Dynamic changes in gene expression in vivo predict prognosis of tamoxifen-treated patients with breast cancer. Breast Cancer Res 12: R39

Tusher VG, Tibshirani R, Chu G (2001) Significance analysis of microarrays applied to the ionizing radiation response. Proc Natl Acad Sci USA 98: 5116-5121

Vegran F, Boidot R, Coudert B, Fumoleau P, Arnould L, Garnier J, Causeret S, Fraise J, Dembele D, Lizard-Nacol S (2009) Gene expression profile and response to trastuzumab-docetaxel-based treatment in breast carcinoma. Br J Cancer 101: 1357-1364

Weigelt B, Lo AT, Park CC, Gray JW, Bissell MJ (2010) HER2 signaling pathway activation and response of breast cancer cells to HER2-targeting agents is dependent strongly on the 3D microenvironment. Breast Cancer Res Treat 122: 35-43

Yap TA, Carden CP, Kaye SB (2009) Beyond chemotherapy: targeted therapies in ovarian cancer. Nat Rev Cancer 9: 167-181

Zorn KK, Bonome T, Gangi L, Chandramouli GV, Awtrey CS, Gardner GJ, Barrett JC, Boyd J, Birrer MJ (2005) Gene expression profiles of serous, endometrioid, and clear cell subtypes of ovarian and endometrial cancer. Clin Cancer Res 11: 6422-6430

This work is published under the standard license to publish agreement. After 12 months the work will become freely available and the license terms will switch to a Creative Commons Attribution-NonCommercial-Share Alike 3.0 Unported License. 